\title{
How to be a 'Good' Anglo-Saxon: Designing and Using Historical Video Games in Primary Schools
}

\author{
Juan Hiriart
}

University of Salford

\begin{abstract}
Over the last decades, digital games have become an important form of historical engagement, with a great potential to influence popular conceptions about the past (Uricchio 2005; Chapman 2012). In spite of the growing academic interest in harnessing this power for historical education, many questions remain unclear with regard to the representational appropriateness of the medium and the theoretical and practical problems involved in designing and using historical computer games in school classrooms. In this chapter, I would like to give an overview of a PhD research set to analyse the potential of digital games for historical education. Adopting a practice-based approach, this research was led by the iterative development of a series of historical game prototypes, designed to explore everyday life in early Anglo-Saxon Britain. At different stages of design,
\end{abstract}

How to cite this book chapter:

Hiriart, J. 2020. How to be a 'Good' Anglo-Saxon: Designing and Using Historical Video Games in Primary Schools. In: Hageneuer, S. (ed.) Communicating the Past in the Digital Age: Proceedings of the International Conference on Digital Methods in Teaching and Learning in Archaeology (12-13 October 2018). Pp. 141-151. London: Ubiquity Press. DOI: https://doi.org/10.5334/bch.k. License: CC-BY 4.0 
the prototypes were evaluated by historians, archaeologists and educators, moving at a later stage to their implementation and testing within the history curriculum of a key stage 2 school classroom (eight to 11 years old). In this phase, qualitative and quantitative data was collected following a pre-post test methodology. This methodology provided valuable insights into children's previous assumptions and naive theories about the past, which were interrogated and in many instances challenged by their experiences within the game. Drawing from this process, this research has contributed to gain a better understanding of the theoretical issues involved in the design and implementation of historical game-based learning methodologies, making empirical connections between educational theory, historical learning, and game design.

\section{Keywords}

Digital Games, Games and Learning, Historical Games, Historical Simulation Games, History Education, History Teaching, Historical game-based Learning, Game Design, Virtual Environments

\section{Introduction}

Digital historical games made their appearance in school classrooms at an early stage in the adoption of educational technology. One of the earlier examples of such experiences is The Oregon Trail (The Oregon Trail 1971), a now-classic educational game simulating the epic westward migration of covered wagons throughout 2,000 miles of the 19th-century US. Since then, many experiences followed but their documentation in academic literature is scattered (McCall 2016). Most of the applications discussed in literature concentrate on secondary education, with the integration of commercial game titles into school curriculums. Among these, Taylor's (2003) implementation of Civilization I and II into the modern history course of a secondary school yielded interesting insights. For this author, games' main potential as historical media resides on three main characteristics: games are interactive, capable of representing complex historical processes in a visual and integrated manner, and can present the past as experienced by those who live it.

A year later, scholars Squire and Barab (2004) explored the pedagogical utilisation of Civilization III (Civilization III, 2001) in formal learning environments. Through three case studies, these authors examined how game engagement, social interactions and understanding evolved in the classroom, drawing conclusions about the role of the game's mediation in the development of the students' understanding. Among many interesting insights, Squire and Barab found that the game itself was not the most important aspect in the learning experience, but rather the social dynamics that surrounded or 
emerged from its implementation in the classroom. The game became a central element of a community of learning, where its educational value heightened as students and teachers played, discussed, analysed, critiqued and expanded the original game.

While both Taylor and Squire and Barab used different versions of Sid Meier's Civilization, the game's complexity and steep learning curve make it challenging to use in primary schools. In this context, the more recent and sandbox game Minecraft, developed by Mojang, has made its way into classrooms of this age group, being used to teach a range of topics while also being adopted for educational research (Nebel, Schneider \& Rey 2016). With an intuitive interaction in an environment entirely made out of textured cubes, this game is simple enough to be learned in one or two hours (Brand \& Kinash 2013), while offering multiple possibilities for the creative exploration and transformation of the game space. By removing and adding blocks with different appearance and properties, players can reconstruct historical places, buildings and artefacts, also becoming part of a community of practice actively sharing their work, process and knowledge through different social media.

While all these experiences and research projects have certainly contributed to the understanding of the potential of digital games for historical education, I would argue that to further the comprehension of this research area it is necessary to expand the study of historical games beyond existing commercial titles, creatively exploring new game mechanics, narrative systems and forms of educational use. To this end, the experimental development of new game forms designed to respond to the specific requirements of teaching history in formal educational settings appears advantageous, or at least complementary to the study of the educational potential of published titles.

In this chapter, my intention is to give an overview of a research project led by the development of a digital game designed with the goal of teaching AngloSaxon history in primary schools. In a first phase, the game was iteratively developed with the participation of historians, archaeologists and history educators, who critically analysed the game prototype at different stages of design. In a second phase, the game was tested in a primary school classroom, where it was evaluated in a real context of use. In the following sections, I will explain some of the key ideas that guided the game's design process, along with the most relevant conclusions that raised from its contextual implementation.

\section{Designing a historical game for the primary school curriculum}

Despite the medieval period of British history forming part of the history curriculum of primary schools in England and Wales, it is often not very well covered, resulting in many pupils finishing their formal education with little or no knowledge of this period. Houghton (2016) in this regard remarks how, for many undergrad students of ancient and medieval history, their 
university courses are in fact their first encounter with the medieval period of British history.

Following the directives of the Department of Education in the United Kingdom, historical education at primary school level should be capable of inspiring the 'pupil's curiosity to know more about the past', think critically and 'understand the complexity of people's lives, the process of change, the diversity of societies and relationships between different groups, as well as their own identity and the challenges of their time' (2013: 1). Can games be used to foster pupils' understanding of life in Anglo-Saxon times, with an acquired sense of the differences and similitudes with our modern lives?

The Anglo-Saxon era can be marked as the time when Germanic tribes Angles, Saxons and Jutes - arrived and settled in Britain after the departure of the Romans around CE 410. This was a time of great change, where the Romano-British cultural and social identity was radically transformed. According to historical and archaeological sources, the finding of the means to survive in the challenging environment of post-Roman Britain was hard and time-consuming. To sustain themselves, early Anglo-Saxons had to dedicate most of their time to finding and/or producing food and drink, an occupation that determined their lives 'both at the basic level of survival and at the level of everyday social interaction' (Crawford 2009: 93). A key part of surviving at this time was the intimate understanding of how the landscape worked: where to find vital resources, how to identify the best soils, where the land would not support farming and where the best hunting was.

Arguably, owing to their interactive and participatory nature, digital games are better equipped to convey these meanings than more traditional forms of historical mediation are. In games, players are not just limited to be external observers of a historical representation but are imbued with the agency of 'doing stuff' with immediate and long-terms effects. This added capacity is given by the simulation of environmental processes and relationships through computer code. The encoding of these processes, however, always implies a certain degree of simplification. How can the intricate relationships between people and environment be translated into computing algorithms while preserving its essential meanings? For Ingold (2000), the livelihood in a natural environment can be abstracted into two distinct processes, conventionally denoted by the terms of collection and production. In most games, the collection of objects from the environment is denoted by their remotion from the game environment, translating their properties to the abstract space of a player's inventory. With regard to the production of new things, Ingold differentiates between the making of things and the processes involved in the growing of things, where humans assist in the reproduction of nature, and derivatively of their own kind' (Ingold 2000: 81).

Conceiving the relationship between early Anglo-Saxons and their environment under Ingold's analytical framework, the game's core mechanics implemented the processes of collecting, making and growing of things. To translate 


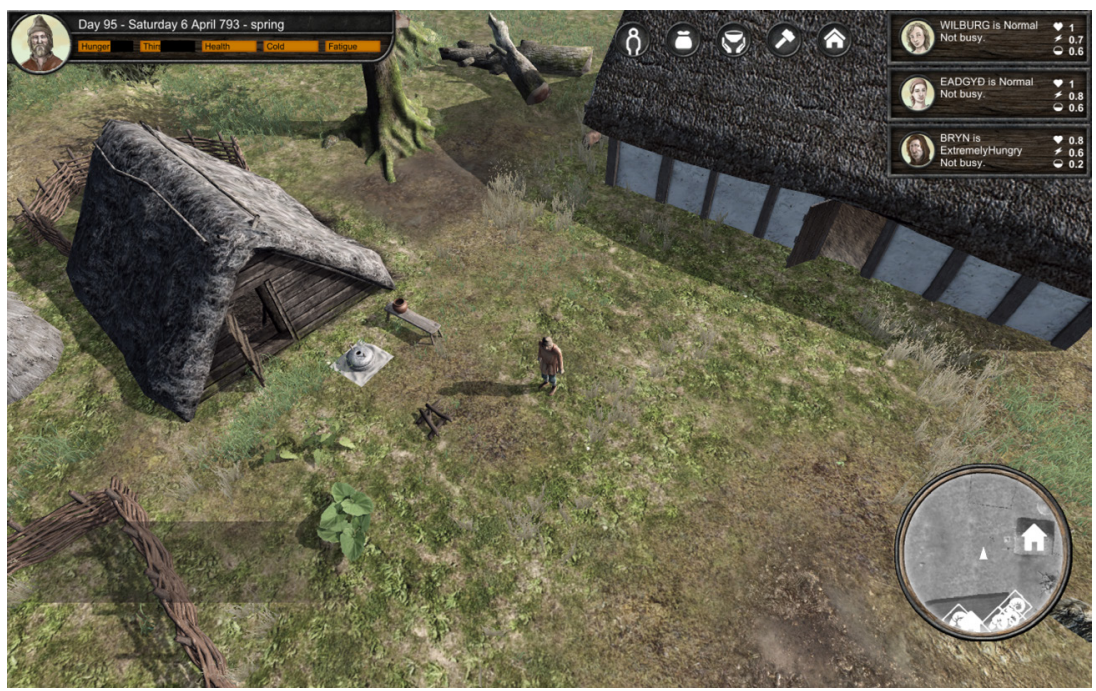

Figure 1: Final Anglo-Saxon game prototype.

these processes into game form, the popular Unity3D engine and editor tools were chosen. With its component-based design approach, this development platform greatly facilitated the translation of Anglo-Saxon everyday life into polygonal computer graphics and computer code. Within the game, players adopted the identity of a free peasant who had to find the means to survive in a simulated post-Roman world. Surviving in this environment demanded the incessant undertaking of a flow of tasks, the 'constitutive acts of dwelling' (Ingold 2000: 195) that make possible to understand the complex processes of human inhabitation. In this sense, the game can be conceptualised as a 'playable taskscape', in reference to the conceptual layer proposed by Ingold to further the understanding of human inhabitation of and intervention in the landscape. To communicate these meanings in game form, however, tasks require to be more than mere survival acts. They need to be also designed to convey cultural and social meanings, communicating how identities, roles and social interactions were defined by divisions of work.

For this, it seemed necessary to incorporate a social level of interaction into the game. This was resolved by the addition of virtual 'family members': nonplayer agents with whom the player interacted primarily through text-based graphic interfaces. Along with providing the opportunity for the player to delegate tasks to the virtual agents, reducing in this way the tediousness of repetitive labouring, these agents also brought the possibility of exploring relevant topics of Anglo-Saxon culture and way of life. Through text-based interactions, children engaged in dialogues designed to foreground the differences between modern and past ways of thinking and living. 


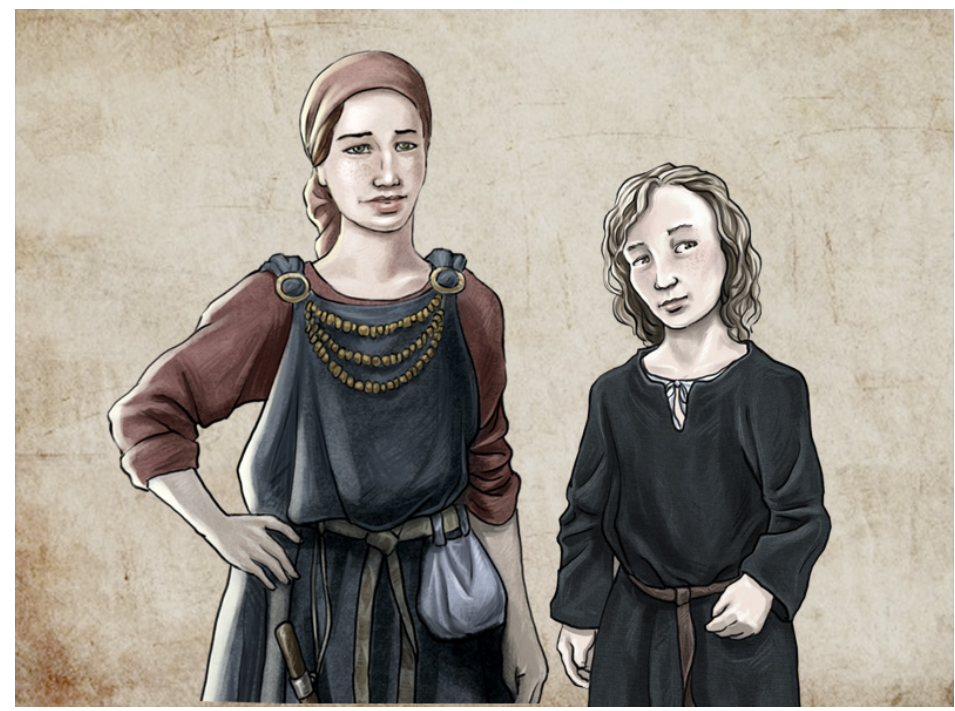

Figure 2: Eadgyð and Wilburg, the characters designed to act as family members within the game.

\section{Testing the game in a primary school classroom}

When the Anglo-Saxon game prototype reached a playable state, the investigation moved to the context of a primary school, where it was implemented and evaluated as part of their history curriculum. This contextual evaluation had a number of goals. Firstly, it sought to explore the ways in which the game could be used in the formal environment of a school classroom in integration with other learning activities. Secondly, it attempted to assess the potential of the game's ludic and narrative systems to communicate how Anglo-Saxons went through their lives. Finally, it sought to evaluate the extent to which the game was able to challenge children's preconceptions about this period.

To this end, the research adopted a pre-post test design. In the first sessions, children were asked to draw how they imagined life in Anglo-Saxon times. In the sessions that followed, children were asked to play the game in a free form, and their playing actions were recorded by the system in a data file stored on each computer. After playing the game, children were asked to draw once more their ideas about the Anglo-Saxon age. In both the first and last drawing sessions, children were informally interviewed, using their drawings as 'conversation drivers' to gain a better understanding of their historical assumptions and playing experiences.

The combination of drawings and mini-interviews proved to be revealing. Through their drawings, children were able to express ideas, emotions and experiences often difficult to articulate in verbal language at their age. In 


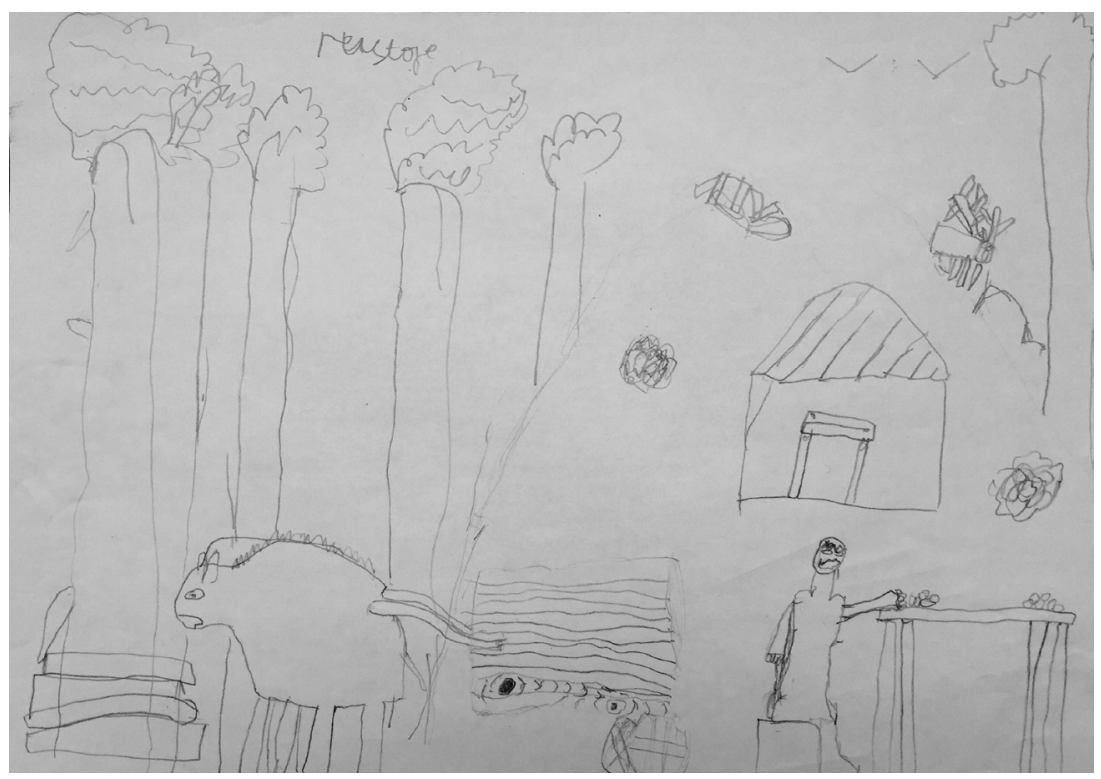

Figure 3: Drawing of a child-imagined Anglo-Saxon world done in a pre-test session.

most cases, these ideas were expressed in the form of vivid narratives, with the drawing's author taking an active role within the representation. In this sense, the historical engagements of drawing and gameplaying with the past shared similar traits. In both activities, children did not just create or interact with historical representations as external observers but situated themselves as active agents within imagined worlds. In these narrative engagements, their interactions revealed as much about their personal identities, lives and world views in the present as about their conceptions about the past. A close study of these visual recounts revealed that children's previous assumptions and naive theories about the Anglo-Saxon age became interrogated and in many instances challenged by their gaming experiences, resulting in dissonances that were later productively addressed in post-play discussions with the teacher and peers.

Through their drawings and comments, children evidenced assumptions about the hardships of everyday life ('life was very hard'), violence ('they used to fight a lot, and people got hurt a lot') and social life ('sometimes they met on campfires to sing songs and tell stories') in Anglo-Saxon times. While playing the game, these assumptions were very much present, coinciding or being at odds with their interpretation of game experiences. These two processes can be analysed through the lens of Piaget's (1973) learning theory. When coinciding, the game narratives were assimilated, reinforcing the previous ideas that children had before interacting with the game. However, when the game 
experiences and previous ideas were at odds, the internal contradiction had to be resolved through a process of accommodation, leading to a subsequent reorganisation and complexification of the children's existing structures of knowledge.

For children to resolve the emerging discrepancies between their historical assumptions and their game experiences, however, the game worked at its best when it was able to engage children empathetically with the dramatic situations presented to their fictional selves. As different authors have pointed out, owing to their capacity to drive players to inhabit the roles and perspectives of their avatars and experience the consequences of their actions and decisions, games are distinctly well suited to support educational activities or programmes where empathy is a key method or goal (Belman \& Flanagan 2009; Isbister 2016). In the next paragraphs, I will centre the attention on some of these situations, reflecting on the ways in which they can be used as triggers of productive teachable moments.

\section{History as conflict and empathy}

According to the evaluation of the game in the school classroom, children interacted with it in contrasting ways. Following Fine (1983), these interactions can be categorised in three different patterns. Firstly, children inhabited the game space through the identity of their avatar, an Anglo-Saxon free peasant with the goal of settling and making a living in a new land. However, while embodying this fictional identity, children did not entirely disconnect from their personal aspirations and modes of thinking in the real world. Rather, their personal identities were very much part of their actions and decisions as they inhabited the goals of their avatars. Finally, children also interacted with the game as players; their motivations and strategies following a progressive understanding of the game's rules, which had to be mastered in order to 'win' or prove themselves better than their peers.

Perhaps nowhere the interplay between these identities became more evident than in the children's interactions with their virtual 'family members'. Despite these agents being designed with a practical function - children could delegate tasks to them, improving their chances of survival - some children deemed them as a burden and refused to feed them or to engage at all with their text-based dialogues. In these cases, it can be said that children engaged with the game primarily as players, a form of consciousness that took precedence over the fictional drivers of the game. In sharp contrast, in other cases children made a significant effort in taking care of the virtual agents, evidencing an engagement with the game's fictional situations as experienced by their avatars. While playing the game in this way, certain narratives set children's fictional and personal identities in conflict, triggering strong emotional responses. This was the case of a particular dialogue in which Wilburg, the player's son, facing 
the uncertainty and possible failure of the farmed land to yield enough food to survive, begs not to be sold as a slave. After interacting with this narrative, many children demanded the teacher to confirm whether a situation of this sort might have happened in medieval times, as well as to know more about what slavery would entail for a child like Wilburg in Anglo-Saxon times.

This observation begs the following questions: to what extent do we wish emotion to become part of historical understanding? What do we gain by letting ourselves feel for or empathise immediately and deeply with particular people, events or situations from the past? These questions have no simple answer. Inasmuch as we can see a defined purpose in engaging empathetically with the past, the proposition does not go without detractors. One of the most important sources of criticism to this kind of engagement involves the 'sins of presentism': the de facto impossibility to divorce ourselves from our present values, beliefs and experiences when looking at the past. I would argue, however, that it is precisely this ability to draw connections between our personal experiences and the particular circumstances affecting historical agents that makes history engaging and motivates us to learn more about the past. After being confronted with Wilbur's drama, children demanded to know more about childhood and slavery in medieval Britain because they cared about the possible fate of this fictional character, with whom they identified at a personal level.

From this line of analysis, I would argue that the most important learning situations triggered by the game were those in which children engaged empathetically and affectively with the circumstances affecting the lives of their avatar or family members. Devoid of this affective plane, the engagement with the game simulation of everyday life through representative tasks had limited educational value. As Robinson remarks, 'one can learn to play simulation games quite well without acquiring much knowledge at all of real history' (2013: 578). 'Real history' is the level of understanding that can only be achieved by empathising with people's lives and experiences. Ultimately, it is only through emotional involvement that students' preconceptions and naive forms of understanding can be challenged and changed. For this to happen, a willingness from the learner's part to enter the liminal space, where the security of the knowledge already known is left behind, is necessary. Commonly, this step is not taken without a good reason. Care provides the reason and purpose to enter the uncomfortable space where learning takes place.

One of the main motivations of this project was the exploration of the ways in which the experimental development of a historical game could inform the research field of historical game-based learning. Reaching the end of this project, and after having iteratively produced and testing an experimental historical game, it is possible to say that this process triggered interesting questions and paths for further exploration. Undoubtedly, the most important outcomes coming from this investigation emerged from the evaluation sessions with archaeologists, historians and history educators, where the design 
and pedagogical use of the game were extensively discussed. This serves as an eloquent indicator of the potential of making as a research method, which is certainly amplified when multiple disciplinary perspectives are integrated into the design process.

\section{References}

Belman, J. and Flanagan, M. (2009). Designing games to foster empathy. International Journal of Cognitive Technology, [online] 14(2): 5-15. Available at: http://www.maryflanagan.com/wp-content/uploads/cogtech-si-g4g-article-1-belman-and-flanagan-designing-games-to-fosterempathy.pdf [Accessed 6 May 2019].

Brand, J.E. and Kinash, S. (2013). Crafting minds in Minecraft. Education Technology Solutions, [online] 55(2013): 56-58. Available at: https:// pure.bond.edu.au/ws/portalfiles/portal/27949355/Crafting_minds_in_ Minecraft.pdf [Accessed 6 May 2019].

Chapman, A. (2012). Privileging form over content: Analysing historical videogames. Journal of Digital Humanities, 1(2): 1-5.

Crawford, S. (2009). Daily Life in Anglo-Saxon England, Wesport: Greenwood World Publishing.

Department of Education (2013). History Programmes of Study: Key Stages 1 and 2 National Curriculum in England. [online] Available at: https://assets. publishing.service.gov.uk/government/uploads/system/uploads/attachment_data/file/239035/PRIMARY_national_curriculum_-_History.pdf [Accessed 6 May 2019].

Fine, G.A. (1983). Shared Fantasy: Role-Playing Games as Social Worlds, London and Chicago, IL: University of Chicago Press.

Houghton, R. (2016). Where did you learn that? The self-perceived educational impact of historical computer games on undergraduates, Gamevironments, 5: 8-45.

Isbister, K. (2016). How Games Move Us: Emotion by Design, London and Cambridge, MA: MIT Press.

Ingold, T. (2000). The Perception of the Environment. London and New York: Routledge.

McCall, J. (2016). Teaching history with digital historical games. Simulation \& Gaming, 47(4): 517-542.

Nebel, S., Schneider, S. and Rey, G.D. (2016). Mining learning and crafting scientific experiments: A literature review on the use of Minecraft in education and research. Educational Technology and Society, 19(2): 355-366.

Piaget, J. (1973). The Future of Education, New York: Grossman Publishers.

Robinson, W.B. (2013). Stimulation, not simulation: An alternate approach to history teaching games. The History Teacher, [online] 46(4): 577-588. Available at: http://www.jstor.org/stable/43264159 [Accessed 6 May 2019]. 
Squire, K. and Barab, S. (2004). Replaying History: Learning World History through Playing Civilization III. Indiana University. [online] Available at: http://website.education.wisc.edu/kdsquire/REPLAYING HISTORY.doc [Accessed 6 May 2019].

Taylor, T. (2003). Historical simulations and the future of the historical narrative. Journal of the Association for History and Computing, [online] 6(2). Available at: https://quod.lib.umich.edu/cgi/t/text/text-idx?c=jahc;view=text;rgn=mai n;idno $=3310410.0006 .203$ [Accessed 6 May 2019].

Uricchio, W. (2005). Simulation, history, and computer games. In: J. Raessens and J. Goldstein, eds, Handbook of Computer Game Studies, Cambridge, MA: MIT Press, pp. 327-338.

\section{Ludography}

Civilization III (2001). Firaxis Games. [Multiple platforms].

The Oregon Trail (1971). Minnesota Educational Computing Consortium \& The Learning Company. [Multiple platforms]. 
